\title{
ĐÁNH GIÁ KẾT QUẢ TRUNG HẠN SỬA VAN HAI LÁ SỬ DỤNG DÂY CHẰNG NHÂN TẠO
}

Nguyễn Văn Nghĩa*

\section{TÓM TẮT}

\section{Mở đầu \& mục tiêu}

Đánh giá kết quả trung hạn sửa van hai lá sử dụng dây chằng nhân tạo tại Viện Tim thành phố Hồ Chí Minh.

Phương pháp: Tiền cứu hàng loạt ca các trường hợp lâm sàng từ tháng năm 2015 đến 2018 trên các số liệu thu thập được từ 27 bệnh nhân được phẫu thuật sửa van hai lá sử dụng dây chằng nhân tạo và khám lại sau phẫu thuật.

Kết quả: Tuổi trung bình của bệnh nhân $51.67 \pm 11.12$ tuổi. Tỷ lệ tái khám đều là $92.6 \%$, mất theo dõi sau mổ là 2 bệnh nhân. Sau 2 năm theo dõi, không có trường hợp tử vong muộn, và $96,3 \%$ không cần mổ lại. Nhiễm trùng vết mổ 3,7\%. 96,3\% trường hợp không hở van hai lá tồn lưu hoặc hở nhẹ; $3,7 \%$ hở trung bình.

Kết luận: Sửa van hai lá sử dụng dây chằng nhân tạo là phương pháp điều trị rất tốt đối với bệnh nhân hở van hai lá do thoái hóa van. Uu điểm của phẫu thuật này là bảo tồn được mô van hai lá, tăng cường cho bộ máy dưới van nhờ dây chằng nhân tạo với độ an toàn cao, ít biến chứng, và bệnh suất cũng như tử suất thấp.

Từ khóa: Sửa sa van hai lá, Dây chằng nhân tạo, Bệnh van tim thoái hóa.

\section{ABSTRACT:}

Background and aim of the study: To present mid-term follow-up results of Mitral Valve Repair with Artifitial Chordae.

Materials and Methods: From 2015 to 2018, 27 patients underwent mitral valve repair by the technique of applying artifitial chordae in the Heart Institute of Ho Chi Minh, Vietnam.

Results: Valve disease was degenerative in most cases. Age ranging of patients $51.67 \pm 11.12$ years. Regular follow-up ratio was $92.6 \%$, lost follow-up 2 cases. Non-fatal complication: No bacterial endocarditis; Infection: $3.7 \%$. No death after 2 years of follow-up overall. Freedom from re-operation at 2 years was $96.3 \%$ ( 1 case of reoperation related to cardiac insufficiency). The grades of mitral regurgitation at 2 years were $96.3 \%$ absent or mild, $3.7 \%$ moderate.

Conclusions: This study showed excellent mortality and morbidity outcomes with mitral valve repair applying artifitial chordae at 2-year follow-up, confirming reliablility and durability of this technique for the patients. This showed a good solution for mitral regurgitation by safe technique, and increase feasibility of mitral valve repair.

Key word: mitral valve repair, artifitial chordae, neo-chord, degenerative disease.

\section{I. ĐẶT VẤN Đî̀}

Phẫu thuật sửa van hai lá hình thành từ đầu thập niên 60 . Vào thời điểm đó, những biến chứng của van nhân tạo còn rất cao, đã thúc đẩy các phẫu thuật viên nghiên cứu và áp dụng các kỹ thuật chỉnh hình van. Những kỹ thuật sửa van khởi đầu còn rất đơn giản và chưa hoàn chỉnh. Dần dần, các kỹ thuật này đã được cải tiến và đa dạng hơn, giúp cho các kết quả sửa van được tốt hơn.

Ngày nay, có thể dùng chỉ PTFE (polytetrafluoroethylene) tạo dây chằng mới thay thế dây chằng bị hư hại, tăng cường cho lá van. Vì vậy, dây chằng nhân tạo Gore-tex là một giải pháp tốt để điều trị hở van hai lá do thoái hóa. [1]

Bệnh hở van hai lá tác động lên cơ quan đích là thất trái, bao gồm những thay đổi hình thái và cấu trúc, vì vậy cần khảo sát kỹ thất trái trước

* Khoa phẫu thuật-Viện Tim TP.HCM. Nguoòi chịu trách nhiệm khoa họ: Nguyễn Văn Nghĩa Ngày nhận bài: 02/08/2020 - Ngày Cho Phép Đăng: 04/09/2020

Phản Biện Khoa học: PGS.TS. Đoàn Quốc Hung PGS.TS. Nguyễn Hũu Uớc 
và sau khi phẫu thuật. Ở một số bệnh viện và trung tâm lớn có phương tiện chẩn đoán hiện đại, bệnh nhân có thể được chụp Cộng hưởng từ giúp đánh giá hình thái và cấu trúc tim, đặc biệt là thất trái một cách toàn diện và chính xác. [5]

\section{Mục tiêu nghiên cứu}

- Đánh giá kết quả ngắn hạn và trung hạn của phẫu thuật sửa sa van hai lá sử dụng dây chằng nhân tạo.

- Đánh giá sự thay đổi về hình thái và cấu trúc thất trái sau phẫu thuật.

II. ĐỐI TƯợNG - PHƯƠNG PHÁP NGHIÊN CÚU

Thiết kế nghiên cứu: Tiền cứu hàng loạt ca.

Đối tượng nghiên cứu:

Dân số nghiên cứu:

Tất cả bệnh nhân được phẫu thuật sửa sa van hai lá sử dụng dây chằng nhân tạo tại Viện Tim Tp.HCM trong thời gian từ năm 2015 đến 2018

\section{Tiêu chuẩn chọn mẫu}

\section{Tiêu chuẩn chọn bệnh}

Tất cả bệnh nhân được phẫu thuật sửa sa van hai lá sử dụng dây chằng nhân tạo trong thời gian từ năm 2015 đến 2018

\section{Tiêu chuẩn loại trù̀}

Bệnh nhân hở van hai lá được thay van nhân tạo

Bệnh nhân sửa van hai lá nhưng dùng các phương pháp khác với dây chằng nhân tạo.

Bệnh nhân hở van hai lá trong bệnh lý nhiều van phối hợp

Kiểm soát sai lệch chọn mẫu:

Sai số do chọn mẫu: định nghĩa rõ ràng đối tượng được đưa vào nghiên cứu căn cứ vào tiêu chuẩn chọn bệnh và tiêu chuẩn loại trừ.

Sai số do thu thập thông tin: chúng tôi ghi nhận thông tin đầy đủ chi tiết và khách quan. Những hồ sơ hoặc số liệu không rõ ràng sẽ được loại ra.

\section{Thu thập số liệu}

Dựa vào bệnh án mẫu, số liệu được thu thập tại Viện Tim thành phố Hồ Chí Minh.

\section{Phân tích và xử lý số liệu}

Số liệu được xử lý bằng phương pháp thống kê, có hỗ trợ bằng phần mềm SPSS 16.0. Biểu đồ tính và vẽ bằng phần mềm Excel.

- Phân tích tổng hợp các dữ kiện lâm sàng, các phương pháp mổ, kết quả phẫu thuật, các biến chứng sau khi mổ.

- Tỉ lệ sống còn theo thời gian, được tính bằng phương pháp Kaplan - Meier.

Phuơng pháp tiến hành: Xác định chiều dài dây chằng nhân tạo và kỹ thuật đặt dây chằng. Nghiên cứu này áp dụng phương pháp đặt dây chằng nhân tạo của tác giả Nguyễn Văn Phan:

Bước 1: Xác định vị trí sa van hai lá

Bước 2: Chọn vị trí van bình thường (kế bên vùng sa van), gắn chỉ 5.0 qua lá trước và lá sau

Bước 3: Khâu chỉ PTFE từ cơ nhú lên vùng lá van bị sa

Bước 4: Chỉ 5.0 căng lên để làm chiều dài chuẩn

Bước 5: Cột chỉ PTFE ngang mức chiều dài chuẩn

Bước 6: Cột chỉ một lần nữa ở mặt dưới lá van

Bước 7: Bơm nước muối sinh lý vào Thất trái để kiểm tra

- Máy siêu âm tim dùng trong nghiên cúu: Loại máy Philips HD7.

\section{Theo dõi ngắn hạn:}

* Sau mổ từ 1 đến 7 ngày, theo dõi các biến chứng phẫu thuật: Chảy máu, đau sau mổ, siêu âm tim.

* Từ 7 ngày sau mổ -3 tháng sau mổ: siêu âm tim kiểm tra độ hở van 2 lá tồn lưu.

Theo dõi trung hạn: Siêu âmtim kiểm tra sau mổ 6 tháng - 1 năm

* Các thông số nghiên cúu gồm: Mức độ hở van hai lá, kích thước lá van hai lá: lá trước, lá sau, kích thước vòng van hai lá, kích thước các buồng tim trái, áp lực động mạch phổi. 


\section{KẾT QUẢ}

\section{Đặc điểm đối tượng nghiên cứu}

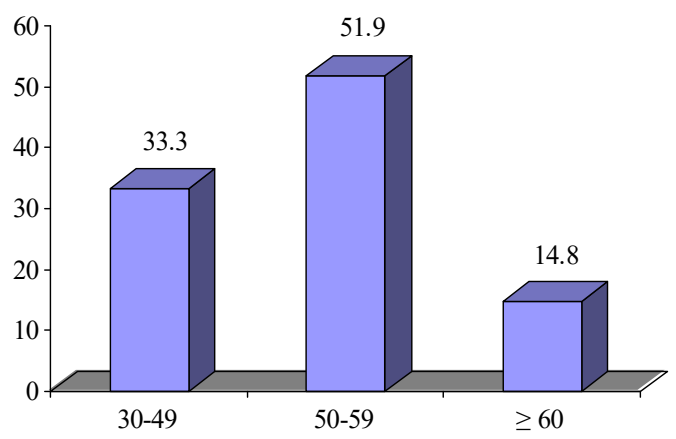

Biểu đồ 1: Đặc điểm nhóm tuổi

Nam chiếm tỷ lệ cao hơn nữ (63\% so với 37\%). Tuổi trung bình là 51.67 (tuổi), lớn nhất là 77 tuổi, thấp nhất là 30 tuổi.

Bảng 1. Phân độ suy tim NYHA trước mổ

\begin{tabular}{|l|c|c|}
\hline NYHA I & 1 & $3.7 \%$ \\
\hline NYHA II & 22 & $81.5 \%$ \\
\hline NYHA III & 3 & $11.1 \%$ \\
\hline NYHA IV & 1 & $3.7 \%$ \\
\hline TỒNG & 27 & $100 \%$ \\
\hline
\end{tabular}

Trong số 27 bệnh nhân đến viện đều có triệu chứng lâm sàng, $81.5 \%$ khó thở khi gắng sức theo phân độ NYHA II. Có 3/27 trường hợp suy tim ( NYHA III ) trước mổ, 1 trường hợp phân độ NYHA I, tình cờ phát hiện bệnh tim khám sức khỏe. 1 trường hợp khác, biểu hiện suy tim nặng, phân độ NYHA IV.

Bảng 2. Số cặp dây chằng được sử dụng

\begin{tabular}{|l|c|c|}
\hline 1 cặp dây chằng & 16 & 59,3 \\
\hline 2 cặp dây chằng & 9 & 33,3 \\
\hline 3 cặp dây chằng & 2 & 7,4 \\
\hline Tổng & 27 & $100 \%$ \\
\hline
\end{tabular}

Bảng 3. Vị trí lá van sử dụng gắn dây chằng nhân tạo

\begin{tabular}{|c|c|c|}
\hline \multicolumn{1}{|c|}{ Vị trí gắn dây chằng } & Tần số & $\mathbf{\%}$ \\
\hline $\mathrm{A} 1$ & 1 & 3.7 \\
\hline $\mathrm{A} 2$ & 17 & 63 \\
\hline $\mathrm{A} 3$ & 3 & 11.1 \\
\hline $\mathrm{P} 1$ & 3 & 11.1 \\
\hline $\mathrm{P} 2$ & 13 & 48.1 \\
\hline $\mathrm{P} 3$ & 3 & 11.1 \\
\hline
\end{tabular}


Nhận xét: Đa số các trường hợp được gắn 1 cặp dây chằng nhân tạo, chiếm $59,3 \% ; 33,3 \%$ bệnh nhân được gắn 2 cặp dây chằng nhân tạo; còn lại, 7,4\% trường hợp phải dùng đến 3 cặp dây chằng nhân tạo.

Trong nghiên cứu này, thương tổn lá trước van hai lá chiếm ưu thế hơn lá sau, $63 \%$ ở A2 so với $48,1 \%$ ở $\mathrm{P} 2$ và thấp nhất là vị trí vùng $\mathrm{A} 1$ (3.7\%) khi đánh giá trực tiếp thương tổn lá van trong lúc phẫu thuật.

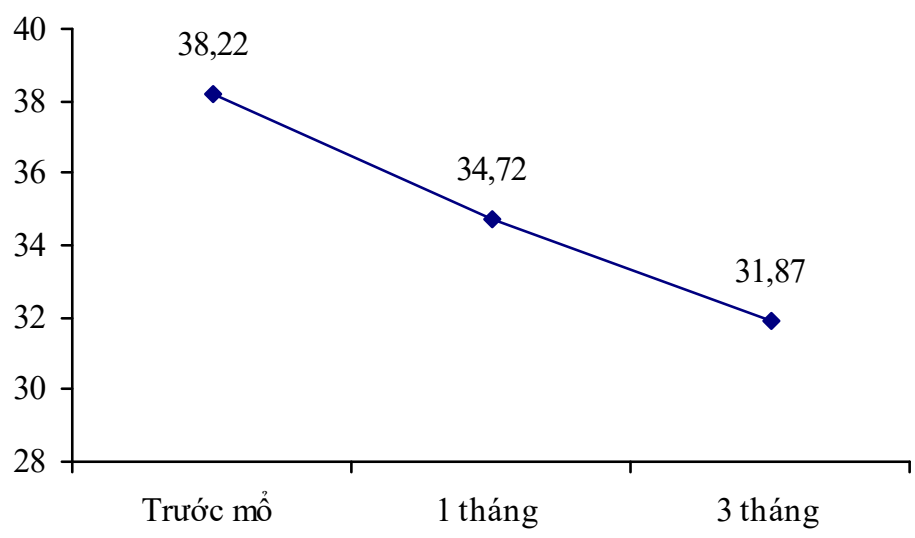

Biểu đồ 2: Sự cải thiện Thất trái sau mổ

Sau phẫu thuật chức năng thất trái hồi phục lại: tim nhỏ lại, giảm kích thước buồng thất trái. Sự cải thiện kích thước buồng tim trái giúp gia tăng phân suất tống máu và ổn định huyết động.

Bảng 4. Các thương tổn của van tim thoái hóa

\begin{tabular}{|l|c|c|}
\hline Thương tổn van hai lá & Tần số & $\%$ \\
\hline Đứt dây chằng & 14 & 51.9 \\
\hline Dài dây chằng & 5 & 18.5 \\
\hline Thiếu dây chằng & 2 & 7.4 \\
\hline Barlow & 6 & 22.2 \\
\hline Tổng & 27 & 100 \\
\hline
\end{tabular}

Trong số 27 trường hợp nghiên cứu, đứt dây chằng là thương tổn chiếm hơn $1 / 2$ trường hợp, do bản chất của bệnh lý thoái hóa van làm cho dây chằng van hai lá mỏng manh dễ bị đứt. Ngoài ra, dây chằng dãn, dài cũng gặp $18.5 \%$ trường hợp, và bệnh lý Barlow chiếm $22.2 \%$. Đây là hình thái tổn thương đặc trưng cho bệnh lý van tim thoái hóa.

Bảng 5. Thông số phẫu thuật

\begin{tabular}{|l|c|c|c|}
\hline & Nhỏ nhất & Lớn nhất & Trung bình \\
\hline Thời gian THNCT (phút) & 51 & 220 & $107.93 \pm 36.87$ \\
\hline Nhiệt độ ${ }^{0} \mathrm{C}$ & 28 & 32 & \\
\hline Thời gian kẹp ĐMC (phút) & 36 & 112 & $70.41 \pm 20.87$ \\
\hline Thời gian thở máy ( giờ ) & 4 & 264 & $41.41 \pm 60.79$ \\
\hline Thời gian hồi sức( ngày ) & 1 & 15 & $3.59 \pm 3.10$ \\
\hline
\end{tabular}




\section{THEO DÕI SAU MỔ}

Kết quả siêu âm tim kiểm tra sau phẫu thuật không ghi nhận hở van hai lá tồn lưu, cũng như không có tắc nghẽn đường ra thất trái ( $\mathrm{SAM})$, kể cả theo dõi ở những lần bệnh nhân tái khám. Không thuyên tắc do huyết khối hoặc viêm nội tâm mạc nhiễm trùng.

Ngoài ra, ghi nhận tràn dịch màng tim chiếm 5/27 trường hợp, được dẫn lưu. Tất cả bệnh nhân tái khám đều. Không có trường hợp tử vong sau phẫu thuật.

\section{BÀN LUẦN}

\section{1. Đặc điểm đối tượng nghiên cứu}

Tuổi: Trong nghiên cứu của chúng tôi, tuổi trung bình là 51.67 tuổi, thấp nhất là 30 tuổi, cao nhất là 77 tuổi. Đây là nhóm tuổi trung niên, phù hợp cho phẫu thuật sửa van hai lá. Nếu phẫu thuật sớm sẽ giúp bệnh nhân về lại cộng đồng với sức khỏe tốt. Nghiên cứu của chúng tôi có độ tuổi trung bình cao hơn tác giả trong nước tuy nhiên lại thấp hơn so với tác giả Tirone E. David. [3]

Giới tính: Theo nghiên cứu của các tác giả trong nước và trên thế giới, tỷ lệ mắc bệnh hở van hai lá nam giới luôn lớn hơn so với nữ giới. Nghiên cứu của Tirone E. David nam chiếm $73.6 \%$, nữ chiếm $26.4 \%$ [4]. Trong nghiên cứu của chúng tôi, nam giới chiếm $63 \%$ và nữ giới là $37 \%$. Có một số y văn lý giải sự tăng tỉ lệ ở nam giới do liên quan đến chấn thương, gắng sức.[6]

\subsection{Phân độ suy tim trước phẫu thuật so với các nghiên cứu khác}

Kết quả phân bố bệnh nhân theo mức độ suy tim trong nghiên cứu của chúng tôi, đa số bệnh nhân có mức độ suy tim NYHA $\geq 2$. Trong đó, độ II chiếm $81.5 \%$ và độ III chiếm $11.1 \%$, và cũng có suy tim độ $I$ và $I V$, cùng chiếm $3.7 \%$. S.Ragnarsson, nghiên cứu năm 2014 ghi nhận: 56\% NYHA II, 44\% NYHA III [6]. Riêng trong nghiên cứu của T.Shibata năm 2015, có $54.6 \%$ trường hợp NYHA II, 45.4\% NYHA III [8].

\subsection{Nhịp tim trước phẫu thuật}

Trong nghiên cứu này, khoảng gần $1 / 2$ số trường hợp có rung nhĩ trước phẫu thuật, mới phát hiện khoảng 2 năm trở lại. Rung nhĩ là một yếu tố liên quan đến nguy cơ cao đột tử và suy tim, làm giảm tỉ lệ sống lâu dài sau phẫu thuật ở bệnh nhân hở van hai lá mạn tính.

Tirone E. David, năm 2013, ghi nhận trong nghiên cứu 476 bệnh nhân, có $78.6 \%$ nhịp xoang, $21.3 \%$ rung nhĩ [4]. Trong nghiên cứu của chúng tôi, tỉ lệ rung nhĩ là $49.1 \%$ và nhịp xoang là $51.9 \%$. Tỉ lệ rối loạn nhịp nói chung cao hơn các tác giả khác. Sự khác biệt này có liên quan đến đường kính nhĩ trái lớn, do thương tổn mạn tính kéo dài nhiều năm.

\subsection{Sự thay đổi về kích thước buồng tim sau phẫu thuật}

Sau phẫu thuật chức năng thất trái hồi phục tốt (Biểu đồ 2): tim nhỏ lại, giảm thể tích thất trái, giảm kích thước buồng thất trái; sự hồi phục thất trái cả thì tâm thu và tâm trương về bình thường [2], [7]. Ngoài ra, kích thước Nhĩ trái cũng cải thiện: trước phẫu thuật, đường kính nhĩ trái trung bình là $50.7 \mathrm{~mm}$, được cải thiện tốt sau mổ 1 tháng với kích thước trung bình là $40.72 \mathrm{~mm}$, và tiếp tục cải thiện về kích thước trung bình là $40.67 \mathrm{~mm}$.

\section{KẾT LUẬN}

- Phẫu thuật gắn dây chằng nhân tạo trong sửa van hai lá là phương pháp điều trị an toàn và hiệu quả cho bệnh nhân hở van hai lá. Qua theo dõi sau phẫu thuật, gần như van hai lá hoàn toàn không hở hoặc hở nhẹ, kích thước buồng tim nhỏ lại (đường kính cuối tâm trương và tâm thu thất trái giảm có ý nghĩa). Không có tử vong sớm và muộn qua theo dõi.

- Tăng phân suất tống máu, kích thước các buồng tim trái giảm, và bệnh nhân phục hồi tốt (theo phân độ NYHA).

\section{KIẾN NGH!}

- Phẫu thuật sửa sa van hai lá sử dụng dây chằng nhân tạo cần được nghiên cứu theo dõi lâu dài hơn để đánh giá đầy đủ về bệnh lý này, và có những kết luận về lâu dài. 


\section{TÀI LIỆU THAM KHẢO}

1. Ngô Chí Hiếu, Đỗ Doãn Lợi (2013), "Nghiên cứu sự thay đổi huyết động, hình thái chức năng thất trái sau phẫu thuật sa van hai lá tại bệnh viện Tim Hà nội". Tạp Chí Y Học Thực Hành, 4, pp. 29-33.

2. Nguyễn Văn Phan (2014), "Kết quả phẫu thuật sửa van hai lá trong bệnh Barlow tại viện tim TP.HCM từ 1994 đến 2012". Tạp chi Phẫu thuật tim mạch và lồng ngục Việt Nam, 6, pp. 17-23.

3. David T. E et al (2013), "Chordal replacement with polytetrafluoroethylene sutures for mitral valve repair: a 25 -year experience". $J$ Thorac Cardiovasc Surg, 145 (6), pp. 1563-9.

4. Kitahara H, Murata M (2016), "Preservation of Mobility of the Posterior Mitral Leaflet After Mitral Valve Repair With
Neochordae Using Loop Technique". Circ J, 80 (3), pp. 663-7.

5. Morris J. D, Penner D. A, Brandt R. L (1964), "Surgical Correction of Ruptured Chordae Tendineae". J Thorac Cardiovasc Surg, 48, pp. 772-80.

6. Ragnarsson S, Sjogren J (2014), "Polytetrafluoroethylene neochordae is noninferior to leaflet resection in repair of isolated posterior mitral leaflet prolapse: a multicentre study". Interact Cardiovasc Thorac Surg, 19 (4), pp. 577-83.

7. Shibata T, Kato Y (2015), "Mitral valve repair with loop technique via median sternotomy in 180 patients". Eur J Cardiothorac Surg, 47 (3), pp. 491-6.

8. Shibata $\mathrm{T}$ et al (2014), "Loop technique for mitral valve repair". Gen Thorac Cardiovasc Surg, 62 (2), pp. 71-7. 